Guo, M., Gurmu, A. and Tivendale, L., 2021. Development of a framework for flood mitigation in Fiji. In: Sandanayake, Y.G., Gunatilake, S. and Waidyasekara, K.G.A.S. (eds). Proceedings of the $9^{\text {th }}$ World Construction Symposium, 9-10 July 2021, Sri Lanka. [Online]. pp. 244-255. DOI: https://doi.org/10.31705/WCS.2021.21. Available from: https://ciobwcs.com/papers/

\title{
DEVELOPMENT OF A FRAMEWORK FOR FLOOD MITIGATION IN FIJI
}

\author{
Mingyuan Guo ${ }^{1}$, Argaw Gurmu ${ }^{2}$ and Linda Tivendale ${ }^{3}$
}

\begin{abstract}
A large portion of infrastructure was flooded by water running off pavements or overflowing from the drainage systems in Fiji. The main objectives of this study are to identify the most suitable drainage management solution to reduce the overflow of the drainage system in Fiji, and to develop a framework of drainage management systems. The literature review was conducted to identify various drainage systems used to mitigate flooding around the world. After the review, the characteristics of Fiji such as climate pattern, location and soil type were analysed in the case study section. Secondary data which was obtained from Australia, Norway, the Netherlands, the U.S., Korea, and China were used in the research. The characteristics of Fiji were then mapped to other countries and a scoring system was created to analyse the suitability of different flood mitigation techniques in Fiji. Finally, multiple flood management strategies were proposed, and a drainage management framework for flood mitigation was developed.
\end{abstract}

Keywords: Fiji; Flood mitigation systems; Framework; HPC.

\section{INTRODUCTION}

It is undeniable that there is a relationship between climate change and flooding events, which seems to be a global issue nowadays. Fiji is one of the Pacific Island Countries and Territories (PICT) which is affected by floods. According to World Bank (2021), due to natural disaster, the economic losses on a per capita basis in Fiji are very high.

Historically, the 3 worst cyclonic activities happened to Viti Levu Island, which is the largest island in Fiji. These include a hurricane that struck in February 1931, Hurricane Kina in 1993, and Cyclone Ami in 2003 (McGree et al., 2010). These cyclonic events have caused a total of 251 fatalities with multi-million dollars loss in infrastructure (Terry et al., 2004; McGree et al., 2010; Yeo and Blong, 2010). However, one of the most recent severe flooding events has shown that cyclonic activities are not the only reasons which lead to disaster in Fiji. Due to Fiji's climate pattern, historical rainfall amount over five days was triggered by a persistent monsoon trough in January 2009, therefore, the Ba, Nadi and Sigatoka rivers in Viti Levu island were severely flooded, and within the Ba River catchment, the flood was reaching $3 \mathrm{~m}$ above the average flood level at the Rarawai mill (McGree et al., 2010). Due to the combined effect from cyclonic activities and local

\footnotetext{
${ }^{1}$ School of Architecture and Built Environment, Deakin University, Australia, guoyo@ deakin.edu.au

${ }^{2}$ School of Architecture and Built Environment, Deakin University, Australia, argaw.gurmu@deakin.edu.au

${ }^{3}$ School of Architecture and Built Environment, Deakin University, Australia, linda.tivendale@deakin.edu.au
} 
climate pattern in Fiji, there are signs which show the frequency of flooding events seems to be increasing in numbers. (BoM and CSIRO, 2011).

Sung and Kim (2012) have mentioned that not all countries have the intention or technology to develop or implement new generation material for flood mitigation. However, Fiji as a developing country needs to act fast to be able to defeat extreme climate condition. As climate changes, public service such as road drainage systems in Fiji is urgently needed to be modified or improved by potential innovative technologies. However, innovative technologies for managing flood are usually established and used in developed countries, therefore, discrepancies in urban and natural environment must be considered under the context of Fiji. Thus, since the popular drainage management systems around the world are mainly case-based and potentially incompatible with the scenario in Fiji, there is a need to develop a context-specific flood mitigation framework for Fiji. To achieve this, a self-adaptive and flexible flood mitigation framework can potentially be used to assist Fiji to save on construction and operational cost of drainage management systems when applying innovative technologies. And then, this fully developed system can alleviate the constraints between urban and natural environment to help Fiji to develop further on infrastructure and prevent extreme flooding events from reoccurring.

Due to the similarities in different countries' climate condition and urban development, common innovative drainage management systems such as Low Impact Development (LID), floodplain and High Permeability Concrete (HPC) have been selected as potential drainage management systems for Fiji. In the U.S., LID as a recently developed stormwater management technique has been used to manage surface water from impervious surfaces to promote infiltration on adjacent pervious surfaces (Holman-Dodds et al., 2003). Holman-Dodds et al. (2003) examined the relative impacts of different forms of urbanization based on experiments on LID. In addition to the LID system, the floodplain system is also one of the innovative water management strategies to reconnect the lakes to the mainstream to reduce the impact of flooding. This strategy sometimes can be incorporated with other infrastructures such as levees. In China, the floodplain system has been considered based on its social value. The government has used floodplain with a moderate number of levees to restore the balance between human and nature. However, in the Netherlands, due to the coastal and low-lying features of the country, levees play the leading role with floodplain in preventing catastrophic flood problems from triggering (Wenger, 2015). In respect to the HPC system, permeable concrete segmental paving has been implemented in the Australian urban road system (Shackel and Pearson, 2003). Based on the general estimation of factors like rainfall pattern, variabilities in climate and soil conditions, Shackel and Pearson (2003) have proved that permeable concrete has very high flexibility and strong adaptability at the pre-design stage of constructing a comprehensive drainage system. From these case studies, it can be seen that due to the increase in urbanised areas of these countries that different flood management strategies have been deployed based on the variation in countries' characteristics such as weather, rainfall pattern, geological information, geographic information and location.

To the authors' knowledge, there are no other researchers who have attempted to solve the drainage system overflow by implementing these new techniques in Fiji. However, flood mitigation techniques from these countries can be modified to be adopted in the context of Fiji. Thus, the objectives of this study are: 
- To review and identify various drainage systems prevalent around the globe.

- To refine the drainage systems by conducting comparative analysis between Fiji and other selected countries.

- To develop a framework of drainage management systems that can be implemented in Fiji by evaluating various methods of optimising or reducing overflow from drainage systems.

\section{LITERATURE REVIEW}

There are about 3 major innovative drainage management systems that are available in the world. These techniques include LID, floodplain/ levees and HPC. In this section, these techniques will be reviewed.

\subsection{LOW IMPACT DEVELOPMENT (LID)}

Low Impact Development (LID) is an integrated drainage management design approach used to address stormwater and environmental impacts often associated with conventional land development. As an effective stormwater management strategy, LID has been given more attention due to its promising findings in the recent 5 years (Huang et al., 2014). Although it is well known for its eco-friendly and relatively low-cost features, the applications of LID vary depending on countries. In fact, from this conducted literature review, model-based techniques are commonly used to predict and simulate the performance of LID practices. Furthermore, by quantifying countries' characteristics such as weather, rainfall pattern, geological information, geographic information, and location into these models that this strategy can be further developed based on either graphical interpretation or mathematical approach to demonstrate a relatively integrated outcome. The following reviews have demonstrated the common LID models and techniques that countries would normally use when the concept of LID has been considered qualitatively and quantitatively.

At present, one of the commonly used model-based techniques to mitigate flooding around the world is called Storm Water Management Model (SWMM) (Huber, 1988; Rossman et al., 2005). SWMM as the basic model has been incorporated into different LID practices for various countries which shows a certain level of compatibility and adaptability to resist climate changes. This type of storm management strategy has been identified across developing countries and developed countries such as China and Norway (Huang et al., 2014; Hailegeorgis and Alfredsen, 2018). In China, Storm Water Management Model version 5 (SWMM5) has been used to simulate the processes in LID practices based on the model which is developed by the U.S. Environmental Protection Agency (USEPA) (Huang et al., 2014). Huang et al. (2014) explored unique approaches to validate and interpret their data based on this model specifically to the characteristics of China. However, the conducted LID research in Norway did not directly apply the SWMM technique. Instead of using this model-based technique, researchers in Norway used SWMM as a control variable to compare their own self-developed mathematical flooding mitigation approach with typical SWMM approaches to enable themselves to understand the advantages and disadvantages of their own systems (Hailegeorgis and Alfredsen, 2018).

Based on the U.S. model, the success of the SWMM5 demonstrates the compatibility of the LID flood mitigation approach in Tianjin, China (Huang et al., 2014). Furthermore, 
Huang et al. (2014) also helped to validate the LID drainage system for the potential to improve stormwater management strategy worldwide. In this case study, Huang et al. (2014) have attempted to use graphical interpretation, a performance radar chart (PRC) to attract attention from the readers by visually presenting the performance and functions of LID alternatives such as bio-retention, cistern system, porous pavement, grass swale and infiltration trench. Under a semi-arid climate condition in China, the efficiency index for water balance was integrated with the PRC in conjunction with the long-term numerical simulation to be staged as the first step ( $\mathrm{Li}$ et al., 2019). And then, the characteristics of that region such as weather, rainfall pattern, geological information, geographic information have been parametrized into the change in total runoff (\%), change in peak flow $(\%)$, rainfall captured by LID on-site $(\mathrm{mm})$, the ratio of saved rainfall on-site and lag time ( $\mathrm{min}$ ) these 5 indicators, and projected as a polygon to demonstrate the optimum LID option (Huang et al., 2014). The outcome of similar research also suggests that porous pavement as one of the LID alternatives has the best performance to reduce runoff and increase infiltration except for lag time under small rainfall events (less than 25.4mm) (Huang et al., 2014; Tsegaye et al., 2019). However, technically speaking that porous pavement can be categorised into other knowledge bodies of flood mitigation strategies such as HPC. On the other hand, since the information is conveyed to the readers through graphics like polygon that it is useful for readers to gain general ideas and information about the potential LID alternatives but not in details. However, in comparison to the case study in mid-Norway that this SWMM5 LID approach is widely adaptable and can be further developed and modified based on countries' and regions' characteristics (Hailegeorgis and Alfredsen, 2018).

\subsection{FLOODPLAIN/LEVEES}

Floodplain is a nature-based flood control measure, which is an area of land adjacent to a stream or river which stretches from the banks of its channel to the base of the enclosing valley walls, and which experiences flooding during periods of high discharge (Reckendorfer et al., 2013). A levee or embankment is an elongated naturally occurring ridge or artificially constructed fill or wall, which regulates water levels. It is usually earthen and often parallel to the course of a river in its floodplain or along low-lying coastlines (Skublics et al., 2016). For the application of floodplain, levees sometimes are needed to maintain the balance between the artificial construction and the natural environment, which means a high level of cooperation among relevant stakeholders is the key for this flood control measure to work. Therefore, based on countries' location and historical climate data that this type of techniques is usually guided by countries' policies, because it usually requires a long-time span to be fully conducted.

In China, Boekhorst et al. (2010) have recognized that floodplain can improve water quality and recover fish stocks based on the perspective of the development of the ecosystem. Therefore, it can be said that the floodplain is not only reconnecting the lakes to the mainstream rivers but also restoring the balance between human and nature (World Resources Institute, 2021). However, the process to restore floodplain is not easy. In the Dongting and Poyang lakes and the Yangtze River regions in 1998, the flooding problems with 1,461 polders, 2.42 million people in 620,000 households created high risk and huge pressure on water and land resources and demands of food supplies (CCICED, 2004). Therefore, the Chinese government started to restore the floodplain by demolishing polders to release floods from 479 polders with an area above 66.7 ha each, and 189,000ha of inundated arable land since 1998 . By the end of 2003, a total of $2,900 \mathrm{~km}^{2}$ land has 
been restored as floodplains with an increase in flood storage capacity up to 13 billion $\mathrm{m}^{3}$ (CCICED, 2004). The situation is different in the Netherlands. Due to the lowland feature, the Netherlands government has deployed multiple flood prevention techniques to adapt to this weakness. The major concept in the Netherlands is to reduce the water level to gain more room. For example, from 2009, the Noordwaard area of the Netherlands has been transformed from an area protected by levees to an area open to high water (Dutch Government, 2006). In the Netherlands, newly constructed flood channels can make river water flow in and out of the Noordwaard during periods of high water, which can lower water levels by $30 \mathrm{~cm}$ at Gorinchem and $60 \mathrm{~cm}$ at the inlet in Werkendam (Dutch Government, 2006). For both China and the Netherland, it can be seen that huge risks have been attached to each of these government-led floodplain approaches, which means large scale flood mitigation projects could frequently involve policies. Therefore, it is important to be familiar with the social context in different countries.

\subsection{High Permeability CONCRETE (HPC)}

Regarding adaptability, High Permeability Concrete (HPC) is worth emphasizing and analysing. As a durable and flexible material, HPC can adapt to any kind of weather, rainfall pattern or soil condition without almost any restriction. Different types of HPC can be incorporated into either the traditional gravity sewer drainage systems or newly invented climate-oriented drainage systems. On the other hand, due to its flexibility that HPC provides a good value for money for many countries or clients to maximise their chance to prevent overflow from extreme rainfall events.

HPC facilities the flexibility, drainage efficiency and budget performance of its related flood management strategies. In Australia, Shackel and Pearson (2003) focused more on the efficiency of the drainage system. Due to heavy rainfall and flash flooding in a relatively short amount of time, Shackel and Pearson (2003) have decided to pursue pavements using porous surfacing including porous asphalt, porous rigid concrete and porous pavers as the potential solutions for Australia. To achieve rapid infiltration of rainwater through vertical openings and drains under Australian rainfall conditions, pavers such as Grass-Stones or Grids, Widened Joint Paving Systems and Eco-Pavers have been considered (Shackel, 2006). Since Eco-Pavers provide the highest infiltration of water among permeable pavements and are based on well-proven conventional paver shapes that this type of HPC has already been applied to the Olympic Boulevard at the Homebush Olympic site, Sydney (Shackel and Pearson, 2003). However, drainage efficiency can also be demonstrated based on pollution removal mechanisms. The conducted research has proven that concrete eco-pavers with base materials can lower the pollutant outflow readings than these conventional impervious concrete surfaces which means that the received rainfall has more pollutants than surface runoff from concrete eco-paving (Tota-Maharaj et al., 2012). Furthermore, after the self-purification of ecopavements, less contaminant has been found in the downstream and groundwater bodies because the transport capacity of the surface runoff has been reduced for the catchment outlet and the groundwater receives filtered infiltrated runoff from the eco-pavements (Tennis et al., 2004). Therefore, the eco-paving technique does not require either groundwater or downstream treatments which can be considered as a huge potential cost saving. As a systematic structural design approach, Shackel and Pearson (2003) have applied the 'LOCKPAVE' computer program published by the Concrete Masonry Association of Australia (CMAA) to design permeable pavements. Since the structural tests of different eco-pavers have shown that they have similar load-spreading properties 
to conventional pavers. Therefore, 'LOCKPAVE' can be directly applied to this type of HPC. As an integrated computer modelling approach, although the 'LOCKPAVE' design program has also taken into account the modelling of material selection of base and subbase layers, it barely considers many factors such as rainfall pattern, variabilities in climate and soil conditions (Shackel and Pearson, 2003). To optimise the functionality of the selected HPC material, a comprehensive analysis that includes these factors would provide clients with enough opportunities to test out and help them to decide the most suitable climate-oriented flood management strategy of using HPC at the early stage of construction. This type of modelling based on conventional computer testing procedures is easily achievable, flexible and can be improved by inputting and assigning more parameters, which could significantly improve the performance of budget control for developing countries or private sectors.

\section{METHODOLOGY}

A comprehensive literature review of papers was conducted to discuss various drainage systems used to mitigate flooding around the world. Based on the library database, research papers addressing common drainage systems such as Low Impact Development (LID), floodplain/levees and High Permeability Concrete (HPC) systems were reviewed.

After the comprehensive literature review, the characteristics of Fiji such as climate pattern, location and soil type were reviewed and analysed in the case study section. The characteristics of Fiji were then mapped to other countries which are reviewed in the literature review section such as China, Norway, the Netherlands, Australia, the U.S., and Korea through a flood mitigation framework. After that, a scoring system was created to analyse the adaptability for Fiji among flood mitigation techniques such as LID, floodplain/ levees and HPC. According to the justification of Sellitto and Burgess (2005), a modified scoring system of the framework was established by considering the value of the criteria $\left(c_{i}\right)$ only. Firstly, the characteristics of Fiji were identified to analyse potential drainage management solutions. Secondly, each country's characteristics were closely examined and compared against the characteristics of Fiji. Thirdly, indices were added to the scoring system subjected to the value of the criteria $\left(c_{i}\right)$ which were either be 1 index 'met criteria' or 0 index 'did not meet criteria'. After all the characteristics in Figure 1 had been cross-checked, all the indices in Table 1 were added up, and the total score for LID, floodplain/ levees and HPC were known. After that, the flood mitigation system which has the highest score in Table 1 would have been the most adaptable drainage management system for Fiji.

At the end of this research, a suitable drainage management framework was proposed for Fiji. Firstly, a flood mitigation framework for Fiji was drawn for comparative analysis based on the characteristics of reviewed countries. This procedure would give relevant stakeholders a deeper understanding of the relationship based on all the mapping factors from various countries. Secondly, from the framework, a scoring system was created. In respect to Fiji, the highest index in the scoring system based on the framework represents the optimal drainage management system choice for Fiji.

\section{CASE STUDY}

In 2009, Viti Levu, one of the largest Pacific islands in Fiji, experienced one of the heaviest rainfalls and unprecedented flooding on the historical record, which led to the 
death of 8 people, thousands of people were displaced, and roads were washed away. Nadi, Sigatoka, Labasa, Ba and many rural villages on this island were heavily affected, especially Nadi. Due to characteristics of Fiji include its location, climate pattern and soil type, there are signs which show the frequency of flooding events seem to be increasing in number and size (Leal, 2013). Furthermore, as climate changes, heavy precipitation events are expected to rise even with relatively small average temperature increases, which could potentially destroy Fiji's infrastructure caused by significant flooding.

Fiji is located in the Pacific region composed of 22 Pacific Island Countries and Territories (PICT), which are scattered over one-third of the globe and covers a total area of some 194,000 square kilometres (World Bank, 2021).

The climate pattern in Fiji is tropical marine, which easily triggers extreme rainfall from November to April every year. Due to Fiji's geographic location that warm seasons bring even heavier rainfall for larger islands, especially inland.

The soil in Fiji can be grouped into 8 major types which include young sandy soils formed around the coast of the islands; fertile, deep agriculturally important alluvial soils occupying the valley bottoms; shallow and moderately-deep, dark coloured, nutrient-rich soils on rolling and hilly land; sandy and silty moderately-deep to deep soils formed from volcanic materials containing particles of unweathered parent material; deep, highly weathered clay-rich soils, often acidic and of low base saturation, derived from basic parent materials; deep, highly weathered oxide-rich clay soils of limited agricultural value; deep sandy soils derived from acid parent materials having clay increases in subsoils, usually strongly weathered and of low base saturation; peats occupying lowlying areas in valleys or on plateaus. Specifically, focus on urbanized areas in Fiji, it can be seen that the soil types are usually combined with beach sand and deep, highly weathered clay-rich soils (McGree et al., 2010).

\section{RESULTS AND DISCUSSION}

The findings which are obtained from the literature review and combined with Fiji's characteristics will be presented in this section. Furthermore, the features of analysed flood mitigation systems and Fiji's drainage management framework will also be presented.

\subsection{FEATURES OF LID, FLOODPLAIN/ LEVEES AND HPC}

LID as an eco-friendly and low-cost flood mitigation system has been applied in multiple countries such as China, Italy, Norway, the U.S., and Turkey. LID also has multiple different sub-categories such as greywater systems, pavements, soak holes/infiltration trench, swales, rainwater harvesting tanks, rain gardens, urban forests, rainwater barrels and stream daylighting to match up with different purposes of flood mitigation. Since LID provides a number of flood mitigation solutions at competitive prices, it can be suitable for developing countries like Fiji. This is due to the relatively small impact of the LID system on the local environment of Fiji, and the relatively higher affordability for the Fiji government to construct the system than others.

Floodplain/ levees are suitable for low-lying countries such as the Netherlands. The major mechanism of floodplain/levees is either demolishing polders to release floods from polders or deploying multiple flood prevention techniques include demolishing polders, flood channel and open to high water. Since agricultural land occupies a relatively large 
portion of the low-lying area in Fiji, it can be said that floodplain/levees are potentially suitable for countries like Fiji. This is due to the similar environmental features among these countries. Besides, in respect to the soil type and location of Fiji, the analysed area of the Netherlands is located in a coastal region with clay soil as its major soil type which is also similar to Fiji.

HPC as an innovative technology demonstrates a significant number of features include high durability, high flexibility, high adaptability, high resistance to climate changes, high-cost efficiency, high drainage efficiency, easily mixed and formed on-site and ecofriendly with low maintenance rate. In respect to Fiji, similar soil types have also been found in the analysed countries such as the U.S. and Australia which have applied HPC as their drainage management systems. In respect to climate pattern, porous asphalt, porous rigid concrete, and porous pavers are the 3 potential flood mitigation solutions of HPC which can be used for various intensity of rainfall in Fiji. Therefore, HPC can be suitable for Fiji.

\subsection{FiJi's Drainage MANAGEMENT FrameWORK FOR FLOOD MitigATION}

Traditionally, countries' scenario has been assessed by individually measuring countries' characteristics. Several methods currently exist for these measurements on an equal basis. For example, 'Soil type' is the same as important as the 'Location' when comparing characteristics among countries. A weighted average approach is the main non-invasive method used to determine the proportional relevance of each component (Sellitto and Burgess, 2005). The synthesis of the weighted average framework was done according to the procedure of Sellitto and Burgess (2005). For a weighted average (WA) calculation, Sellitto and Burgess (2005) have considered assigning a weight for each observation $\left(w_{i}\right)$ against the value of the criteria $\left(c_{i}\right)$. The cohort of the value of the criteria $\left(c_{i}\right)$ was divided into two groups according to the value assigned to the criteria. To identify any feature, this value will either be 1 'met criteria' or 0 'did not meet criteria'. In this paper, to understand how 'Soil type', 'Rainfall Pattern and Weather' and 'Location' as targeted groups to regulate potential drainage management solutions for Fiji, the associated characteristics from each country have been compared against selected flood mitigation systems. According to the justification of Sellitto and Burgess (2005), to reduce the human error caused by subjectivity, a modified scoring system of the framework has been established based on the consideration of the value of the criteria $\left(c_{i}\right)$ only.

Numerous papers have been analysed based on 6 countries and a framework has been developed. The framework will be interpreted as follows. For example, the major soil type in the analysed area of the Netherlands is clay soil under floodplain/levees mitigation system is given the same equivalence value as the major soil type in Fiji as it is also clay soil. Therefore, 1 index will be given to the Netherlands in the column of 'Floodplain/ Levees' in Table 1. To correlate each group in the framework with the characteristics of Fiji to find the most adaptable flood management technique for Fiji, Table 1 has been created. The top row of Table 1 has been divided into 3 sections which are the names of the reviewed flood mitigation techniques including LID, floodplain/ levees and HPC. After that, each column of the reviewed flood mitigation techniques has been further divided into 3 sub-categories which are 'Soil Type', 'Rainfall Pattern and Weather' and 'Location' for mapping the 3 groups in the framework on the left side of Figure 1. Furthermore, the left end column of Table 1 represents the reviewed countries' names of 
flood mitigation techniques. Finally, the bottom row of Table 1 represents the total scores for each reviewed flood mitigation technique for the adaptability of Fiji.

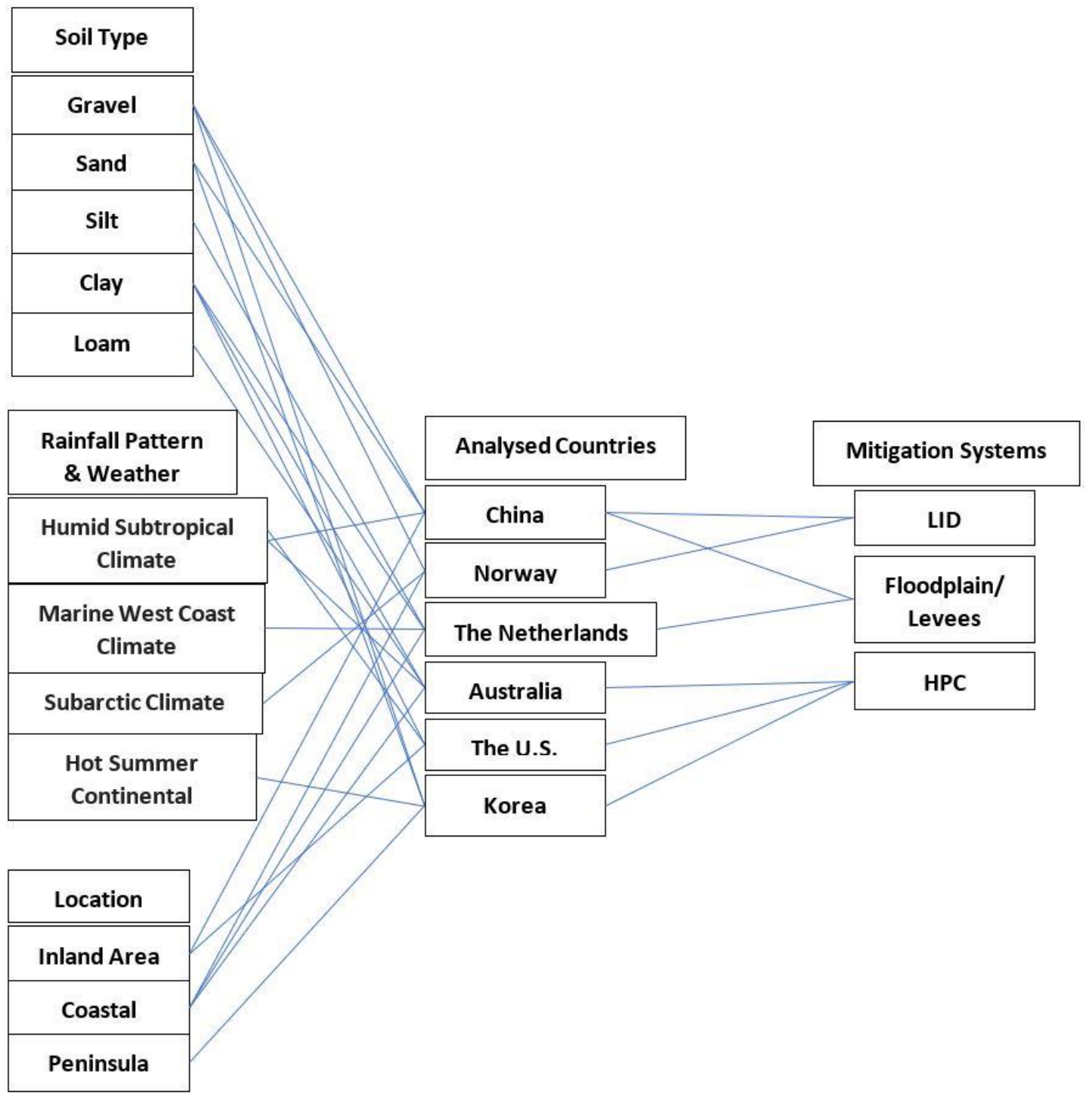

Figure 1: Flood mitigation framework for Fiji

Table 1 shows the scoring system of the developed framework for Fiji. This scoring system for Fiji is based on the 5 characteristics of Fiji. For the geological information and geographic information in the case study section, it is known that the major soil type in urbanized areas of Fiji is beach sand and clay soil. In respect to weather and rainfall pattern, tropical marine is the climate pattern in Fiji featured with extreme rainfall from November to April every year. For the location, Fiji is an island country. Therefore, the 3 groups include 'Soil type', 'Rainfall Pattern and Weather' and 'Location' in the framework from Figure 1 will be compared against with above Fiji's characteristics, and if there is a match that 1 index will be added to that flood mitigation technique for that specific country under one of the 3 groups in Table 1. For example, the major soil types in the Netherlands are silt and clay from Figure 1, therefore, 1 index will be added to the cell where sub-categorized column 'Soil Type' under the section of 'Floodplain/Levees' intercepts with the row of 'The Netherlands' in Table 1 because clay soil is one of the major soil types in Fiji. 
Table 1: Scoring system of the framework based on Fiji's characteristics

\begin{tabular}{|c|c|c|c|c|c|c|c|c|c|}
\hline \multirow[b]{2}{*}{ Countries } & \multicolumn{3}{|c|}{ LID } & \multicolumn{3}{|c|}{ Floodplain/ Levees } & \multicolumn{3}{|c|}{ HPC } \\
\hline & $\begin{array}{l}\text { Soil } \\
\text { Type }\end{array}$ & $\begin{array}{c}\text { Rainfall } \\
\text { Pattern } \\
\text { and } \\
\text { Weather }\end{array}$ & Location & $\begin{array}{l}\text { Soil } \\
\text { Type }\end{array}$ & $\begin{array}{l}\text { Rainfall } \\
\text { Pattern } \\
\text { and } \\
\text { Weather }\end{array}$ & Location & $\begin{array}{c}\text { Soil } \\
\text { Type }\end{array}$ & $\begin{array}{c}\text { Rainfall } \\
\text { Pattern } \\
\text { and } \\
\text { Weather }\end{array}$ & Location \\
\hline China & - & 1 & - & - & - & - & - & - & - \\
\hline Norway & - & - & 1 & - & - & - & - & - & - \\
\hline Netherlands & - & - & - & 1 & - & 1 & - & - & - \\
\hline Australia & - & - & - & - & - & - & 1 & 1 & 1 \\
\hline U.S. & - & - & - & - & - & - & 1 & 1 & - \\
\hline Korea & - & - & - & - & - & - & - & - & - \\
\hline Total & & 2 & & & 2 & & & 5 & \\
\hline
\end{tabular}

The scoring system in Table 1 can be considered as a part of an optimization process for Fiji. Therefore, with the considerations of the framework from Figure 1 and the scoring system from Table 1, a suitable drainage management framework for flood mitigation is developed for Fiji. From Table 1, HPC is the most adaptable flood mitigation system for Fiji as it has the highest index 5 in total to satisfy all the 5 characteristics of Fiji. This result is achieved after the scoring system has been used to crosscheck all the mapping factors with the framework from Figure 1.

The scoring system in Table 1 has yielded four important findings for design considerations of drainage management system in Fiji.

- In this study, although the major soil types in Fiji are beach sand and clay soil, only clay soil has been considered because an artificial drainage system cannot be built in the sand.

- Loam is the mix based on sand, silt and clay (Ni et al., 2016). Although both loam and clay soil are the major soil types in Australia, only 1 index has been added to the cell where the column of 'HPC' intercepts with the row of 'Australia', because the major soil type in Fiji is clay soil only.

- There is no reviewed country has a tropical marine climate pattern like in Fiji, therefore, the humid subtropical climate pattern has been considered as it is the closest climate pattern to Fiji.

- Although Australia is an island country, the size of Australia is much larger than the size of Fiji.

Therefore, in this study, it is assumed that only countries located in the coastal area will be granted 1 index based on the characteristics of Fiji.

Based on the developed flood mitigation framework for Fiji, professionals in Fiji such as government consultants and engineers can apply this framework quite easily. Firstly, government consultants can initiate the data collection process to shortlist a number of flood mitigation systems because they have easier access to data than most other relevant stakeholders. After all the collected data has been categorised as input to be allocated into the flood mitigation framework for Fiji (refer Figure 1), engineers and government consultants can work together and use the scoring system (refer Table 1) to calculate the index for each flood mitigation system. After all the scores have been calculated for the shortlisted flood mitigation systems, government consultants can propose the system 
which has the highest index in the feasibility study report of infrastructure development of Fiji.

\section{CONCLUSIONS}

To sum up, a suitable drainage management framework for flood mitigation has been established for Fiji. This framework provides relevant stakeholders with opportunities to make their best decisions on infrastructure development for Fiji. In the context of Fiji, the most adaptable flood management technique is HPC based on Fiji's characteristics including weather, rainfall pattern, geological information, geographic information, and location. Based on the framework and the scoring system, multiple potential flood management strategies have also been proposed. The developed framework can be used as a guideline by relevant stakeholders such as governments, builders, engineers, consultants, and contractors.

Nonetheless, since HPC is only one part of the flood management strategy, other underdrain systems should be explored further. Underdrain strategies such as full infiltration, partial infiltration and full attenuation might be useful to improve the adaptability of HPC. However, since only secondary data has been used in this study, future researchers can investigate other drainage systems by collecting primary data.

Although the framework still has room for improvement, it is believed that HPC can be an applicable drainage management system for Fiji to mitigate flooding and resist future climate changes.

\section{REFERENCES}

Australian Bureau of Meteorology (BoM) and Commonwealth Scientific and Industrial Research Organisation (CSIRO), 2011. Climate change in the pacific: Scientific assessment and new research [Online]. Available from: https://www.pacificclimatechangescience.org/publications/reports/reportclimate-change-in-the-pacific-scientific-assessment-and-new-research/ [Accessed 18 May 2021].

Te Boekhorst, D.G., Smits, T., Yu, X., Li, L., Lei, G. and Zhang, C., 2010. Implementing integrated river basin management in China. Ecology and Society, 15(2), p. 23.

China Council for International Cooperation on Environment and Development (CCICED), 2004. Promoting integrated river basin management and restoring China's living rivers [Online]. Available from: http://www.cciced.net/cciceden/POLICY/rr/prr/2004/201205/t20120529_82753.html [Accessed 18 May 2021].

Dutch Government, 2006. Spatial planning key decision: Room for the river [Online]. Available from: https://www.ruimtevoorderivier.nl/english/ [Accessed 18 May 2021].

Hailegeorgis, T.T. and Alfredsen, K., 2018. High spatial-temporal resolution and integrated surface and subsurface precipitation-runoff modelling for a small stormwater catchment. Journal of Hydrology, 557, pp. 613-630

Holman-Dodds, J.K., Bradley, A.A. and Potter, K.W., 2003. Evaluation of hydrologic benefits of infiltration based urban storm water management. Journal of the American Water Resources Association, 39(1), pp. 205-215.

Huang, J.J., Li, Y., Niu, S. and Zhou, S.H., 2014. Assessing the performances of low impact development alternatives by long-term simulation for a semi-arid area in Tianjin, Northern China. Water Science and Technology, 70(11), pp. 1740-1745.

Huber, W., 1988. Storm water management model user's manual version 4. Athens, GA: U.S. Environmental Protection Agency, Environmental Research Laboratory.

Leal, W., 2013. Climate change and disaster risk management. Berlin, Heidelberg: Springer. 
Li, Q., Wang, F., Yu, Y., Huang, Z., Li, M. and Guan, Y., 2019. Comprehensive performance evaluation of lid practices for the sponge city construction: A case study in Guangxi, China. Journal of Environmental Management, 231, pp. 10-20.

McGree, S., Yeo, S. and Devi, S., 2010. Flooding in the Fiji Islands between 1840 and 2009. Risk Frontiers. Sydney: Macquarie University.

Ni, L., Suleiman, M.T. and Raich, A., 2016. Behavior and soil-structure interaction of pervious concrete ground-improvement piles under lateral loading. Journal of Geotechnical and Geoenvironmental Engineering, 142(2), p. 04015071.

Reckendorfer, W., Funk, A., Gschöpf, C., Hein, T. and Schiemer, F., 2013. Aquatic ecosystem functions of an isolated floodplain and their implications for flood retention and management. Journal of Applied Ecology, 50(1), pp. 119-128.

Rossman, L., Dickinson, R., Schade, T., Chan, C., Burgess, E.H. and Huber, W., 2005. SWMM5: The USEPA's newest tool for urban drainage analysis. In: $10^{\text {th }}$ International Conference on Urban Drainage, Copenhagen, pp. 1-8.

Sellitto, C. and Burgess, S., 2005. Towards a weighted average framework for evaluating the quality of web-located health information. Journal of Information Science, 31(4), pp. 260-272.

Shackel, B., 2006. Design of permeable paving subject to traffic. In: $8^{\text {th }}$ International Conference on Concrete Block Paving, November 2006, pp. 6-8.

Shackel, B., and Pearson, A., 2003, May. Permeable concrete eco-paving as best management practice in Australian urban road engineering. In: $21^{\text {st }}$ Australia Road Research Board (ARRB) Conference, Cairns Qld, Australia.

Skublics, D., Blöschl, G. and Rutschmann, P., 2016. Effect of river training on flood retention of the Bavarian Danube. Journal of Hydrology and Hydromechanics, 64(4), pp. 349-356.

Sung, C.Y. and Kim, Y.I., 2012. Void ratio and durability properties of porous polymer concrete using recycled aggregate with binder contents for permeability pavement. Journal of Applied Polymer Science, 126(S2), pp. 338-348.

Tennis, P., Leming, M. and Akers, D., 2004. Pervious concrete pavements. Skokie, Illinois: Portland Cement Association.

Terry, J., Mcgree, S. and Raj, R., 2004. The exceptional flooding on Vanua Levu Island, Fiji, during tropical cyclone Ami in January 2003. Journal of Natural Disaster Science, 26(1), pp. 27-36.

Tota-Maharaj, K., Grabowiecki, P., Babatunde, A. and Coupe, S.J., 2012, May. The performance and effectiveness of geotextiles within permeable pavements for treating concentrated stormwater. In: $16^{\text {th }}$ International Water Technology Conference (IWTC), pp. 1-13.

Tsegaye, S., Singleton, T.L., Koeser, A.K., Lamb, D.S., Landry, S.M., Lu, S., Barber, J.B., Hilbert, D.R., Hamilton, K.O., Northrop, R.J. and Ghebremichael, K., 2019. Transitioning from gray to green (g2g) A green infrastructure planning tool for the urban forest. Urban Forestry and Urban Greening, 40, pp. 204-214.

Wenger, C., 2015. Better use and management of levees: Reducing flood risk in a changing climate. Environmental Reviews, 23(2), pp. 240-255.

World Bank, 2021. Pacific islands - Disaster risk reduction and financing in the Pacific [Online]. Available from: $\quad$ https://documents.worldbank.org/en/publication/documentsreports/documentdetail/218201468189869828/pacific-islands-disaster-risk-reduction-and-financingin-the-pacific [Accessed 18 May 2021].

World Resources Institute, 2021. Controlling Yangtze river floods: A new approach [Online]. Available from: https://www.wri.org/our-work/project/world-resources-report/controlling-yangtze-river-floodsnew-approach [Accessed 18 May 2021].

Yeo, S.W. and Blong, R.J., 2010. Fiji's worst natural disaster: The 1931 hurricane and flood. Disasters, 34(3), pp. 657-683. 